\title{
OTIONOMICS
}

Revista de economía, empresa y sociedad

EDITORIAL

\section{Vectores de sostenibilidad: visiones desde la economía}

\author{
Albert Puig Gómez \\ Profesor de los Estudios de Economía y Empresa de la UOC. Director del Máster Universitario de Ánàlisis Económica \\ de la UOC
}

En 1987, cuando se publicó el informe de la Comisión de Naciones Unidas sobre Desarrollo y Medio Ambiente titulado Nuestro futuro común (aunque habitualmente conocido como Informe Bruntland, en honor al presidente de la comisión y ex primer ministro noruego), el término sostenibilidad no era de uso común. Treinta y cuatro años después, la palabra ha pasado a formar parte de nuestro vocabulario y de nuestra cotidianidad. Cualquier decisión de consumo o de producción se exige que lleve el sello de la sostenibilidad.

El documento citado se basaba fundamentalmente en la cuestión medioambiental y definía la sostenibilidad como «la satisfacción de las necesidades de la generación presente sin comprometer la capacidad de las generaciones futuras para satisfacer sus propias necesidades».

Sin duda, la lucha contra el cambio climático es el principal desafío que la comunidad internacional debe afrontar en la actualidad, dado que la desestabilización de algunos sistemas planetarios pone en riesgo la propia supervivencia de la especie humana. Sin embargo, el concepto de sostenibilidad ha ido evolucionando hacia una concepción mucho más amplia que la exclusivamente ecológica, en la que se incluye la necesidad de buscar una triple sostenibilidad: la medioambiental, la social y la económica.

La sostenibilidad medioambiental pone el acento en preservar los equilibrios ecológicos y la biodiversidad; la social busca la cohesión de la población, promoviendo niveles satisfactorios de calidad de vida y bienestar; mientras que la sostenibilidad económica implica -aunque en general no se reconoce muy explícitamente- que las actividades que buscan las otras dos sostenibilidades -la ambiental y la social- deben ser rentables, pues de lo contrario no tendrán lugar al no responder a la lógica de acumulación capitalista.

Es bajo este planteamiento, por ejemplo, que se aprobaron, por parte de la asamblea general de Naciones Unidas en septiembre de 2015, los objetivos de desarrollo sostenible (ODS), los cuales establecen alcanzar 17 objetivos -y 169 metas- que combinan aspectos de las tres sostenibilidades.

En el número de Oikonomics que presentamos nos aproximamos a los tres ámbitos o vectores de la sostenibilidad. Y lo hacemos a través de siete artículos que los tratan de forma transversal; es decir, ningún trabajo se reduce al análisis de uno de los vectores en particular, sino que lo hace en el marco de un tema específico, tomando los elementos de cada una de las dimensiones que considere más relevantes. El resultado es el buscado, un issue que trate el concepto de la sostenibilidad como un todo.

El primero de los artículos, el de Joan Torrent, contextualiza el tema, analizando la conexión que ha realizado la economía científica entre el desarrollo económico y la sostenibilidad social. Partiendo de la idea clásica del valor en el capitalismo, el artículo revisa las principales aportaciones que la economía clásica, neoclásica, heterodoxa y las síntesis modernas han efectuado sobre la posibilidad de un desarrollo económico socialmente sostenible. A partir de esta revisión, se llega a la necesidad de construir una nueva economía del valor sostenible y se analizan sus principales dimensiones, en especial el papel que deberían jugar las empresas, los mercados y el Gobierno. 
A continuación, Zora Kovacic trata la propuesta de la economía circular, la cual promete convertir las preocupaciones por la sostenibilidad en sinergias que promuevan el crecimiento económico. En este sentido, por ejemplo, señala que la economía circular se ha convertido en una de las políticas estrella del Pacto Verde Europeo y está cada vez más presente a todos los niveles. Sin embargo, a pesar del gran entusiasmo generado por esas políticas públicas, la idea de una economía circular es también fuente de mucha controversia a nivel científico, ya que la idea de que es posible recircular la mayoría de los materiales y productos va en contra de las leyes de la termodinámica.

En el tercer artículo, Federico Demaria plantea que la humanidad se enfrenta a dos desafíos principales: la creación de una economía resistente y justa que genere prosperidad para todos y proteger la salud humana a nivel planetario. Y que ello debe hacerse avanzando hacia la reducción de los impactos ambientales por debajo de los umbrales de los límites planetarios. En este sentido, argumenta que el crecimiento económico no es compatible con la sostenibilidad ambiental, ni siquiera el basado en un keynesianismo verde, e introduce el decrecimiento, esto es, una reducción de la producción y el consumo en los países industrializados, como un medio para lograr la sostenibilidad ambiental, la justicia social y el bienestar.

Por su parte, Aurèlia Mañé-Estrada analiza la geopolítica de la energía en el marco del sistema capitalista. En la primera parte explica el nacimiento de la geopolítica de la energía fósil y cómo las hegemonías se fundamentan en el control territorial de las fuentes energéticas. Posteriormente, en la parte más arriesgada del artículo, reflexiona sobre hacia dónde podría evolucionar la geopolítica de las renovables. La principal conclusión es que, dadas las características de las fuentes renovables, la geopolítica que se establezca será el fruto de una elección. La cuestión que dilucidar es si esta elección seguirá orientándose a utilizar las relaciones energéticas internacionales como mecanismo para la hegemonía mundial y la financiación del sistema.

En el quinto artículo, Hug March expone cómo, en el marco de la tendencia general que ha tenido lugar en las últimas cuatro décadas de traspaso del poder económico de la industria a las finanzas, también el sector del agua se ha sumado a esa tendencia a la «financiarización». Este cambio ha remodelado profundamente la relación entre las infraestructuras y las empresas que median en un bien tan esencial para la ciudadanía, la producción y el medio ambiente como es el agua. El artículo presenta los debates en torno a la financiarización del ciclo hídrico, a través del ejemplo del desarrollo de nuevas infraestructuras hídricas en la ciudad de Londres.

Seguidamente, Eduard Alvarez y Mireia Hernández exponen que las ciudades, como aglomeraciones poblacionales y centros de producción, son actores directamente interpelados por los objetivos de desarrollo sostenible. Señalan que la explosión de la trama urbana y la ocupación del territorio sin precedentes que ha tenido lugar en los últimos años, sustentadas en la promoción urbanística, la ocupación del suelo y en unas infraestructuras de transporte que no han sido planificadas de forma coordinada con estos proyectos urbanísticos, son insostenibles. En la parte final del artículo reflexionan sobre cómo avanzar hacia un modelo de ciudad más sostenible.

Y para cerrar el número, Agustí Pérez-Foguet expone cómo los avances en los últimos años han permitido disponer de una metodología de medida de la pobreza multidimensional que ha facilitado concretar y operativizar el concepto. En paralelo, señala que se han propuesto y consolidado propuestas de pobrezas «sectoriales", con entidad conceptual propia, y que el vínculo entre las dimensiones de la pobreza multidimensional y las pobrezas sectoriales es diverso. El autor argumenta que reducir las pobrezas sectoriales a dimensiones de pobreza multidimensional limita su utilidad e impacto y propone avanzar en la caracterización multidimensional de dichas pobrezas sectoriales.

En síntesis, el número 16 de Oikonomics se acerca, a través de siete artículos elaborados por ocho autores de reconocido prestigio, al principal reto que afronta la humanidad, el de la sostenibilidad, un reto que ya no es de futuro sino para su más inmediato presente. Con ello deseamos contribuir al debate alrededor de un concepto que va más allá de su dimensión ecológica y que debe tomar también en consideración sus dimensiones sociales y económicas. 
Cita recomendada: PUIG GÓMEZ, Albert. Vectores de sostenibilidad: visiones desde la economía. Oikonomics [en línea]. Noviembre 2021, n. 16. ISSN: 2339-9546.

DOI: https://doi.org/10.7238/o.n16.2108

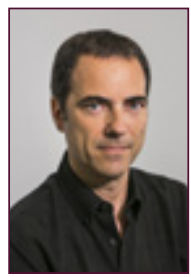

\section{Albert Puig Gómez}

apuiggo@uoc.edu

Profesor de los Estudios de Economía y Empresa de la UOC. Director del Máster Universitario de Ánàlisis Económica de la UOC

Imparte docencia en Política Económica y Economía Mundial e investiga los efectos de las inversiones extranjeras en las economías receptoras a través del marco analítico de las cadenas globales de valor.

Los textos publicados en esta revista están sujetos -si no se indica lo contrario- a una licencia de Reconocimiento 4.0 Internacional de Creative Commons. Puede copiarlos, distribuirlos, comunicarlos públicamente, hacer obras derivadas siempre que reconozca los créditos de las obras (autoría, nombre de la revista, institución editora) de la manera especificada por los autores o por la revista. La licencia completa se puede consultar en https://creativecommons.org/licenses/by/4.0/deed.es_ES.

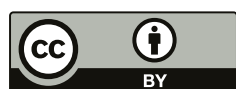

